\title{
A Case of Pica on a 6-Year-Old Child from Medan
}

\author{
Ismarika Ismarika, Elmeida Effendy*(iD) \\ Department of Psychiatry, Faculty of Medicine, Universitas Sumatera Utara, Medan, Indonesia
}

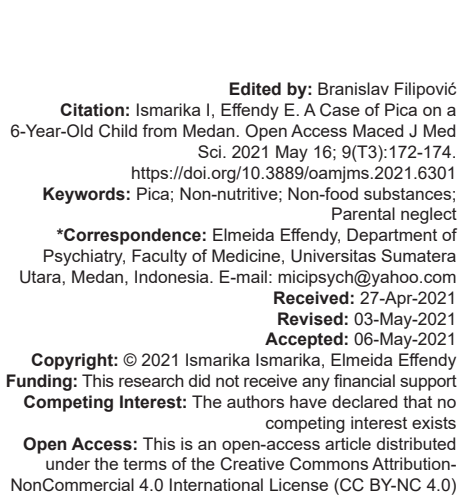

\begin{abstract}
BACKGROUND: In 2013, in the feeding and eating disorder category of the Diagnostic and Statistical Manual of Mental Disorders (DSM-5), pica was included as a diagnosis. Eating one or more non-nutritious, non-food substances continuously for at least 1 month is an important characteristic of pica. Children who participate in pica eat products that differ greatly but also include paper, plastic, fabric, dirt, paint, rocks, soap, and cigarette butts. This purpose of this case report is to determine the symptoms and diagnosis of pica in child.
\end{abstract}

CASE REPORT: A 6-year-old girl was brought to the Psychiatry Clinic of North Sumatera University Hospital with her mother due to her unusual behavior of eating stuff including paper, sawdust, crayon, cloth, and ice cubes. This on since the little girl was 3 years of age. One week earlier, the little girl experienced diarrhea before being admitted to the psychiatry clinic. In this case, the diagnosis of pica used the DSM-5 criteria.

CONCLUSION: We hope that this case report about pica can figure out more about this particularly unusual behavior, which can occur even in normal children in which parental neglect may precipitate its occurrence. As clinicians, we can detect the symptoms and signs of pica in children to prevent further complications.

\section{Introduction}

In 2013, in the feeding and eating disorder category of the Diagnostic and Statistical Manual of Mental Disorders, pica was included as a diagnosis. Eating one or more non-nutritious, non-food substances continuously for at least 1 month is an important characteristic of pica. Eating non-nutritious, non-food substances are unacceptable for the developmental stage of the child and not part of a normative feature that is culturally or social supported. Medical accounts dating back several centuries mimic the modern-day description of pica. Historically, pica has been considered either as an accompaniment to conditions such as pregnancy or developmental disabilities or an indication of medical problems such as iron deficiency. Pica is not limited to infants or adults with intellectual developmental disabilities, but it is often associated with children with developmental delays. Children who engage in pica eat products that differ greatly but also include paper, plastic, fabric, dirt, paint, rocks, soap, and cigarette butts. This dangerous conduct occurs through gender, age, ethnicity, socioeconomic status, and geographical area, while prevalence increases with the severity of intellectual disability [1], [2].

Pica exists globally. In childhood, adolescence, or adulthood, the onset of pica may occur, while childhood onset is most frequently reported. Pica can occur in children who otherwise normally develop, whereas it seems more likely to appear in adults with the scope of intellectual disability or other psychiatric disorders [1].
Most often found in mentally disabled individuals by professionals working with children. Children with special sensory needs are often seen, such as those seeking oral stimulation, and children on the spectrum of autism may be included. Pica, nevertheless, in normally developing children, it may also occur in regular clinical examination, the likelihood of this activity being present is frequently underestimated. In children aged 18 months -6 years, the incidence is highest. Population studies have shown that $20-30 \%$ of children between the ages of $1-6$ have experienced pica; with age, the frequency decreases. Pica is more prevalent than is normally understood either because the disorder may be missed by doctors or under-reported by patient/parents [3], [4].

Pica's etiology is poorly known and likely to be multifactorial. Proposed pathways differ from biological to psychosocial. The relationship between pica and micronutrient deficiencies, including iron, calcium, and zinc, has been well described. Pica has also been linked to deprivation, parental neglect, and malnutrition in infants. In the presence of a coexisting psychiatric illness, it may be present and there may be abundant support that disorders that contribute to negative nutritional status, malabsorption, or anemia may be associated with it [5].

Pica may have significant medical effects. Poisoning, abdominal perforation, blockages, or the development of bezoars may have these effects; in some situations, the actions may have fatal effects. Despite this risk, there are few studies investigating its prevalence and incidence [3]. In Germany, a new population-based 
analysis involving 804 children that aged $7-14$ years and their parents found that pica behavior was confirmed to have occurred in $12.3 \%$ of children at least once with $5 \%$ of chronic pica behavior reported [6].

Using a multidisciplinary team strategy, pica is best managed. Physicians, social workers, dieticians, psychologists, and dentists can be included in the team. In pica, pharmacological treatments are infrequently suggested [5]. Intensive staffing and near-continuous behavioral monitoring are standard approaches to pica care to interrupt any attempts at this potentially life-threatening activity proactively [7]. A child with pica condition in an inclusive childcare setting, a functionbased evaluation was performed. Results indicate that pica was preserved by access to adult attention [8].

A thorough physical examination can also be undertaken as part of the evaluation. A lot of data about the gross and fine motor skills of an infant, expressive and receptive language skills, and the preferences and engaging style of the parents can be gleaned by observing the child and parent when taking history [9].

\section{Case Report}

We are presenting a case of A, a 6-year-old girl, a Muslim, and from mining ethnicity, who was admitted to the psychiatry outpatient clinic of North Sumatera University Hospital in August 2020. Her mother complained of witnessing her daughter eating unusual stuff, such as paper, sawdust, crayon, ice cubes, and clothes. This has been going on since the girl was 3 years old. The girl's mother started to notice this strange behavior when A's little brother was born. Ever since A started to consume strange non-food stuff quietly. A's mother stated that $A$ is very hard to control which often leads the mother into a boiling rage. Yet the girl keeps taking that unusual stuff instead of all her mother's discipline approaches. A week earlier, A had diarrhea after consuming a crayon, but a general physician has discharged her. The general physician further suggested A's mother take her to a psychiatrist.

During the interview, we found that our patient was fully conscious, cooperative in terms of behavior and psychomotor activities, her face is appropriate to her age, and her speech was appropriate with normal flow and productivity. We noted that our patient showed an appropriate affect with euthymic mood but with a tensed emotion. No delusion or perception disorders were found.

Our patient, $A$, is the first daughter and has a 3-year-old little brother. Her mother stated that A's father has always been expecting to have a son, which leads to the father giving more attention and affection toward the son. The father was also known to often discipline our patient, which caused anger in the little girl being displaced to her little brother.
Interestingly, we found that $A$ is quite a friendly child. We noted that $A$ complained of her parents not being affectionate and attentive enough toward her, so often that she was abandoned. It made her aggressive and irritable toward her little brother. We did not find any traumatic history and physical examination within normal limits from the interview.

Treatment option for this type of patient is behavior therapy in which parental attention and support are fully required, including to ensure that all dangerous substance or unusual stuff are kept away out of the children's reach. The nutritional need of the children is met so that the children are prevented from any further complications.

\section{Discussion}

Pica can occur at any age. It is more commonly reported in children with developmental disorders, but it is not uncommon to occur in normal children. In this particular case report, parental neglect may contribute to the developmental of pica. Children tend to distract their attention by eating unusual nonnutritive stuff. As for our patient, the physical problem also occurred, as the girl had diarrhea after consuming a crayon. Other reported complications of pica include poisoning, intestinal perforation, malnutrition, and iron deficiency [6].

Treatment strategy for the patient can be carried out in the form of a behavior intervention strategy in which parental attention and support are required every step of the way and ensure that the child's nutritional needs are fulfilled. Pharmacotherapy is uncommon, but the administration of selective serotonin reuptake inhibitor in three teenagers with pica was ever reported [5].

\section{Conclusion}

We hope that this case report about pica can figure out more about this particularly unusual behavior which can occur even in normal children in which parental neglect may precipitate the development of this disorder. Consequently, when this disorder is abandoned, it may further harm the patient.

\section{References}

1. American Psychiatric Association. Diagnostic and Statistical Manual of Mental Disorders. $5^{\text {th }}$ ed. Washington, DC: American Psychiatric Association; 2013. p. 329-32. https://doi.org/10.1176/ 
appi.books. 9780890425596

2. Call NA, Simmons CA, Movers JE, Alvarez JP, Clinical outcomes of behavioral treatments for pica in children with developmental disabilities. J Autism Dev Disord. 2015;45(7):2104-14. https:// doi.org/10.1007/s10803-015-2375-z

PMid:25636679

3. Bryant-Waugh R. Feeding and eating disorders in children. Psychiatr Clin N Am. 2019;42(1):157-67.

\section{PMid:30704636}

4. Leung AK, Hon KL. Pica: A common condition that is commonly missed an update review. Curr Pediatr Rev. 2019;15(3):164-9. https://doi.org/10.2174/1573396315666190313163530

PMid:30868957

5. McNaughten B, Bourke $T$, Thompson A. Fifteen-minute consultation: The child with Pica. Arch Dis Child Educ Pract Ed. 2017;102(5):226-9. https://doi.org/10.1136/ archdischild-2016-312121

PMid:28487433
6. Hartmann AS, Poulain T, Vogel M, Hiemisch A, Kiess W, Hilbert A. Prevalence of pica and rumination behaviors in German children aged 7-14 and their associations with feeding, eating, and general psychopathology: A population-based study. Eur Child Adolesc Psychiatry. 2018;27(11):1499-508. https://doi. org/10.1007/s00787-018-1153-9 PMid:29675593

7. Muething C, Call NA, Clark S. An evaluation of differentia reinforcement in the treatment of pica. Dev Neurorehabil. 2019;23:321-7.

8. Ledford JR, Barton EE, Rigor MN, Stankiewicz KC, Chazil KT, Harbin ER, et al. Functional analysis and treatment of pica on a preschool playground. Behav Anal Pract. 2019;12(1):176-81. https://doi.org/10.1007/s40617-018-00283-9

PMid:30918781

9. Borowitz KC, Borowitz SM. Feeding problems in infants and children assessment and etiology. Pediatr Clin North Am. 2018;65(1):59-72. https://doi.org/10.1016/j.pcl.2017.08.021 PMid:29173720 